\title{
Case Report \\ Behçet Disease-Like Symptoms with a Novel COPA Mutation
}

\author{
E. Anderson, ${ }^{1}$ J. Hatch, ${ }^{2}$ J. Cardinal, ${ }^{3}$ D. Langguth, ${ }^{4,5}$ and D. Coman $\mathbb{D}^{1,2,5,6,7}$ \\ ${ }^{1}$ Virtus Diagnostics, Brisbane, Australia \\ ${ }^{2}$ Department of Paediatrics, The Wesley Hospital, Brisbane, Australia \\ ${ }^{3}$ Cardinal Bioresearch, Brisbane, Australia \\ ${ }^{4}$ Department of Immunology, Sullivan Nicolaides Pathology, Brisbane, Australia \\ ${ }^{5}$ The School of Medicine, Griffith University, Gold Coast, Australia \\ ${ }^{6}$ The School of Medicine, The University of Queensland, Brisbane, Australia \\ ${ }^{7}$ Department of Metabolic Medicine, The Queensland Children's Hospital, Brisbane, Australia
}

Correspondence should be addressed to D. Coman; david.coman@hotmail.com

Received 13 October 2019; Revised 9 December 2019; Accepted 14 December 2019; Published 11 January 2020

Academic Editor: Christos Yapijakis

Copyright (C) 2020 E. Anderson et al. This is an open access article distributed under the Creative Commons Attribution License, which permits unrestricted use, distribution, and reproduction in any medium, provided the original work is properly cited.

COPA syndrome is a recently described autosomal dominant disorder with key immune dysregulation caused by defects within the COPA gene. These mutations lead to endoplasmic reticulum stress and autoimmune response with upregulation of Th17 cytokines. The clinical phenotype of COPA syndrome primarily comprised pulmonary disease, arthritis, and renal disease secondary to immune dysregulation, with onset of symptoms commonly in the first decade of life. Herein, we describe a family with an attenuated Behçet-like phenotype of COPA syndrome, further expanding the phenotypic understanding of this syndrome.

\section{Introduction}

COPA syndrome (OMIM 616414), also known as autoimmune interstitial lung, joint, and kidney (AILJK) disease, is caused by mutations in the coatomer subunit alpha $(C O P A)$ gene located on chromosome 1q23.2 (OMIM 601924) [1, 2]. COPA is a crucial component of the coatomer protein complex 1, required to mediate vesicular retrograde trafficking from the Golgi to the endoplasmic reticulum (ER). Impaired retrograde vesicle transport results in ER stress, subsequent unfolded protein and systemic inflammatory responses, and a variety of human diseases [3-6].

COPA syndrome has only recently been identified, initially in five families with various COPA mutations [2]. It is an autoimmune disease with early onset, usually by five years of age [2], and generally with a greater female-to-male ratio $[2,7]$. It is inherited in an autosomal dominant pattern, with variable penetrance and expressivity that can also reflect gender bias [8]. The majority of patients with COPA syndrome have clinical manifestations of lung pathology (interstitial lung disease or diffuse alveolar haemorrhage), renal disease, and, most predominantly, arthritis [2, 8]. Inflammatory markers are typically elevated, including C-reactive protein and erythrocyte sedimentation rate (ESR). Additional indicators of immune dysregulation seen in COPA syndrome patients include positive ANA titres as well as increased rheumatoid factor and cytoplasmic and perinuclear anti-neutrophil antibodies [1]. Upregulation of Th17-priming cytokines and a significant skewing of CD4+ T cells to the Th17 phenotype in COPA syndrome patients [2] are further evidence of the autoimmune inflammatory processes involved in this rare disease.

Behçet disease (OMIM 109650) is a rare autoimmune/ autoinflammatory disorder with widespread vasculitis [9]. Most common symptoms are oral and genital ulcers, uveitis, and joint inflammation. It generally presents later than is seen for COPA syndrome, usually in the $20 \mathrm{~s}$ and $30 \mathrm{~s}$. Whilst disease distribution is equal between men and women, men are affected with more severe symptoms and earlier age of onset [10]. Behçet disease is associated with the HLA-B gene [11], although this correlation is not currently well understood. There is no clear inheritance pattern, and it is likely 
that a combination of genetic and environmental factors is involved in development of this condition. This report describes a family with a Behçet-like phenotype with a novel sequence variant in the COPA gene that segregates with the affected individuals, further expanding the genotypic and phenotypic understanding of this syndrome.

\section{Case Report}

The family discussed herein (the proband, the proband's mother, and the proband's brother) demonstrates a consistent phenotype of inflammatory lesions, neuropathic symptoms, polyarthritis, and bursitis. Their symptoms were attenuated compared to those described for COPA syndrome to date, more closely resembling a Behçet-like phenotype with no demonstrated pulmonary or renal dysfunction and no increased autoimmune serology markers.

The proband, aged 32 at diagnosis, suffers from debilitating polyarthropathy, predominantly affecting the hands and knees, with widespread bursitis. She also suffers from chronic fatigue and widespread pain, migraines, recurrent severe buccal ulcers, and chronic diarrhoea. She was diagnosed with Behçet disease and commenced on multiple immune modulators for symptom control. After taking adalimumab, her disease worsened, with increasing ulceration and diarrhoea, and the emergence of a follicular hypovascular skin rash. During episodes of worsening clinical symptoms, her ESR was found to be elevated with a normal CRP. Her renal function testing has remained normal, with no evidence of renal involvement to date. Immunological testing of her $\mathrm{B}$ and $\mathrm{T}$ cells found that her CD19 and CD20B cells were low, at $<0.01 \times 10^{9} / \mathrm{L}$. All other autoimmune serological testing has been normal. The proband has been on dapsone and folic acid long term, with any trial reduction resulting in an increase of arthritic symptoms.

The proband's mother, aged 64, has accelerated restricted mobility due to hip adductor tendonitis and bursitis, polyarthritis with synovial cysts, inflammatory lesions of the mouth, and vasculitis of the ileum. In addition to these more classic Behçet-like symptoms, she has a history of recurrent stroke-like symptoms and peripheral neuropathy. In an attempt to control predominantly her arthritic symptoms, she was trialled on secukinumab, a monoclonal antibody that binds the IL-17A protein. IL17A would likely be upregulated in COPA syndrome due to the predominance towards Th17 cells, and this increase has been previously reported [2]. She reported short-term subjective symptomatic relief, before experiencing a relapse of arthritis six months later, and secukinumab was ceased in preference for a trial of adalimumab. Her ileal vasculitis was treated with prolonged-release oral budesonide resulting in good symptomatic relief.

The proband's brother, now deceased, demonstrated a very similar phenotype to his mother and sister, complicated further by severe bilateral trigeminal neuralgia and Crohn's disease.

None of the family members had symptoms in childhood suggestive of Behçet disease. To date, none have demonstrated pulmonary or renal symptomatology; however, the proband has been diagnosed with urinary tract infections with increasing frequency. Lung function testing has not occurred in the proband, mother, or brother.

Whole exome sequencing (WES) identified an NM_001098398 c.2558G > A; p.Gly853Asp (het) variant in the COPA gene segregating with disease amongst the family. The family members did not have any identified variant in the TNFAIP3 gene which is causative for A20 haploinsufficiency, an autoinflammatory syndrome that resembles Behçet disease [12]. The COPA variant identified here has been previously reported on dbSNP with an allele frequency of 0.0007 on ExAC. The variant overlaps with an evolutionary constrained element (detected using SiPhy- $\omega$ and SiPhy- $\pi$ statistics). The conservation across 28 species is described with PhyloP (score: 2.83). GERP identifies constrained elements in multiple alignments by quantifying substitution deficits (score: 5.93). In silico analyses on the variant also included a SIFT score of 0.23 , a Polyphen score of 0.12 , and a BLOSUM score of -1 . The mutation site of this variant is a start site for an alternatively spliced transcript (ENST00000545284).

After enrichment of all coding and flanking intronic regions of the genes mentioned above, sequencing analysis was performed using an Illumina HiSeq platform. The quality criteria required at least 10 reads per base; however, $97.7 \%$ of targeted regions achieved $\times 100$ coverage and $99.7 \%$ achieved $\times 10$ coverage. Only sequence variations with an allele frequency $<1 \%$ were considered pathogenic. The WES and subsequent Sanger sequencing were performed in the laboratories of Macrogen, a company with CLIA certification.

\section{Discussion}

Table 1 outlines the currently reported mutations and the corresponding phenotypical features described for COPA syndrome, including comparison between other published data and the family in this report. The lack of renal or pulmonary involvement for this family expands the current understanding of the spectrum of COPA syndrome phenotype.

The autoimmunity seen in COPA syndrome skews CD4+ T cells toward the Th17 phenotype and promotes activation of the type 1 interferon pathway $(2,5)$. This increase in Th17 cells also increases the expression of the Th17related stimulant cytokines, specifically IL-1 $\beta$, IL-6, IL-17A, and IL-23 [1]. The literature is yet to understand the exact relationship between Th17 and the resultant autoimmunity observed. Our index case having only short-lived relief from arthritic symptoms with secukinumab supports that Th17 is but a single mediator in a complex pathway. It is not yet fully clear whether increased Th17 is causative to, or caused by, COPA inflammatory symptomatology. Whilst various immunosuppressive regimes have been effective in some shortterm improvement or stability particularly of the pulmonary symptoms of COPA syndrome, these may be limited in their long-term effectiveness [7].

Th17 and related interleukins such as IL-17A have a significant role in gastrointestinal disorders such as 
TABLE 1: Clinical and molecular presentations of COPA syndrome.

\begin{tabular}{|c|c|c|c|c|c|c|c|c|}
\hline & Proband & Mother & Brother & {$[2]$} & [8] & [13] & [14] & [7] \\
\hline Sex & Female & Female & Male & $\begin{array}{c}8 \text { men } \\
13 \text { women }\end{array}$ & $\begin{array}{l}2 \text { women } \\
2 \text { men }\end{array}$ & 1 man & 1 woman & $\begin{array}{c}3 \text { men } \\
11 \\
\text { women }\end{array}$ \\
\hline $\begin{array}{l}\text { Pulmonary } \\
\text { features }\end{array}$ & Nil & Nil & Nil & $\begin{array}{l}21(100 \%) \\
\text { DAH, ILD }\end{array}$ & FB, ILD, CT & ILD & ILD & $\begin{array}{c}14 \\
(100 \%) \\
\text { ILD } \\
7(50 \%) \\
\text { DAH }\end{array}$ \\
\hline $\begin{array}{l}\text { Neuropathic } \\
\text { features }\end{array}$ & $\begin{array}{l}\text { Stroke-like } \\
\text { episodes } \\
\text { Peripheral } \\
\text { neuropathy }\end{array}$ & $\begin{array}{l}\text { Chronic } \\
\text { fatigue }\end{array}$ & $\begin{array}{l}\text { Trigeminal } \\
\text { neuralgia }\end{array}$ & Dyskinesia & $\begin{array}{l}\text { Neuromyelitis } \\
\text { optica }\end{array}$ & NR & NR & NR \\
\hline $\begin{array}{l}\text { Arthritic } \\
\text { features }\end{array}$ & $\begin{array}{l}\text { Polyarthritis } \\
\text { Synovial } \\
\text { cysts } \\
\text { Bursitis }\end{array}$ & $\begin{array}{c}\text { Polyarthritis } \\
\text { Bursitis }\end{array}$ & Nil & $\begin{array}{c}20(95 \%) \text { arthritis } \\
\text { AVN }\end{array}$ & $\begin{array}{c}\text { Arthritis } \\
\text { AVN }\end{array}$ & Arthritis & Arthritis & $\begin{array}{c}14 \\
(100 \%) \\
\text { arthritis }\end{array}$ \\
\hline $\begin{array}{l}\text { Gastrointestinal } \\
\text { features }\end{array}$ & $\begin{array}{c}\text { Ileal } \\
\text { vasculitis }\end{array}$ & Nil & $\begin{array}{l}\text { Crohn's } \\
\text { disease }\end{array}$ & NR & Liver cysts & GORD & NR & NR \\
\hline Renal features & Nil & Nil & Nil & Glomerulonephritis & $\begin{array}{c}\text { CCC } \\
\text { Nephrolithiasis } \\
\text { pyelonephritis }\end{array}$ & NR & NR & $\begin{array}{c}3(21 \%) \\
\text { renal } \\
\text { disease }\end{array}$ \\
\hline ANA & Negative & NR & NR & $14(67 \%)$ & NR & NR & Positive & $\begin{array}{c}12 \\
(86 \%) \\
\text { positive }\end{array}$ \\
\hline ANCA & Negative & NR & NR & $15(71 \%)$ & NR & NR & Negative & $\begin{array}{c}9(64 \%) \\
\text { positive } \\
10\end{array}$ \\
\hline $\mathrm{RF}$ & Negative & NR & NR & $9(43 \%)$ & NR & NR & Positive & $\begin{array}{c}(71 \%) \\
\text { positive }\end{array}$ \\
\hline Autoantibodies & Negative & NR & NR & $18(86 \%)$ & NR & NR & Negative & NR \\
\hline COPA mutation & p.Gly853Asp & p.Gly853Asp & p.Gly853Asp & $\begin{array}{l}\text { p.Glu241Lys } \\
\text { p.Lys230Asn } \\
\text { p.Asp243Gly }\end{array}$ & p.Arg233His & p.Trp240Arg & p.Arg233His & NR \\
\hline
\end{tabular}

ANA: antinuclear antibody; ANCA: anti-neutrophil cytoplasmic antibody; AVN: avascular necrosis; CCC: clear cell carcinoma; CT: carcinoid tumour; DAH: diffuse alveolar haemorrhage; FB: follicular bronchitis; ILD: interstitial lung disease; NR: not reported; RF: rheumatoid factor.

inflammatory bowel diseases [15], yet this symptom has not been previously reported with COPA syndrome. The proband in this study suffering ileal vasculitis and the proband's brother having Crohn's disease may be evidence for an inflammatory bowel disease-associated phenotype as part of the COPA syndrome spectrum.

Neuropathic symptoms in COPA syndrome have also not been widely reported previously; however, all three of the patients in this report manifested with various neural symptomatology. ER stress has been linked with central nervous system inflammation and neuronal dysfunction [16] and may be another aspect of the broader COPA syndrome phenotype.

All COPA mutations previously identified in the literature map to exons eight and nine in the highly conserved WD40 functional domain of the COPA protein $[2,8,13,14,17,18]$. The p.Gly853Asp variant identified in this report is instead found in the C-terminal domain of the protein which could account for the attenuated phenotype in these individuals compared to phenotypes from WD40-domain mutations. The mutation site identified in this paper is a start site for an alternatively spliced transcript, and therefore, protein transcription may be affected. Functional studies are required to determine if the variant does affect transcription from this splice site as well as to confirm that this variant is indeed causative for the family members' symptoms. Whilst in silico analyses as defined above (SIFT, Polyphen, BLOSUM) do not predict a pathogenic effect of this variant, these analyses do not take into account the splice site activity of this variant and the effect of different transcripts (which may be expressed in different tissues). Altered splice site activity again may account for the attenuated phenotype outlined in this paper and does require functional studies to elucidate further regarding the pathogenicity of this mutation.

Although the variant has been reported on dbSNP with an ExAC allele frequency of 0.007 , the true frequency of the disease is difficult to determine as the phenotypic association with mutations in the COPA has only been described recently and has variable penetrance. We suggest the syndrome may be underrecognised and underdiagnosed. 
This family's unique Behçet-like phenotype adds to understanding of the clinical spectrum of COPA syndrome phenotype. It presents evidence that mutations in the COPA gene may have a broader phenotype than previously reported and that consideration should be given when diagnosing unexplained arthritic, vasculitic, and/or neuropathic symptoms. Further functional studies are needed to confirm that this variant does have a deleterious effect on protein function and is specifically the causative agent for this phenotype.

\section{Conflicts of Interest}

The authors declare that they have no conflicts of interest.

\section{Acknowledgments}

The authors would like to thank the family involved as well as the Kevin Milo Trust for making this work possible.

\section{References}

[1] T. J. Vece, L. B. Watkin, S. K. Nicholas et al., "Copa syndrome: a novel autosomal dominant immune dysregulatory disease," Journal of Clinical Immunology, vol. 36, no. 4, pp. 377-387, 2016.

[2] L. B. Watkin, B. Jessen, W. Wiszniewski et al., "COPA mutations impair ER-Golgi transport and cause hereditary autoimmune-mediated lung disease and arthritis," Nature Genetics, vol. 47, no. 6, pp. 654-660, 2015.

[3] C. Hetz and F. R. Papa, "The unfolded protein response and cell fate control," Molecular Cell, vol. 69, no. 2, pp. 169-181, 2018.

[4] S. A. Oakes and F. R. Papa, "The role of endoplasmic reticulum stress in human pathology," Annual Review of Pathology: Mechanisms of Disease, vol. 10, no. 1, pp. 173-194, 2015.

[5] S. Wang and R. J. Kaufman, "The impact of the unfolded protein response on human disease," The Journal of Cell Biology, vol. 197, no. 7, pp. 857-867, 2012.

[6] K. Zhang and R. J. Kaufman, "From endoplasmic-reticulum stress to the inflammatory response," Nature, vol. 454, no. 7203, pp. 455-462, 2008.

[7] J. L. Tsui, O. A. Estrada, Z. Deng et al., "Analysis of pulmonary features and treatment approaches in the COPA syndrome," ERJ Open Research, vol. 4, no. 2, pp. 1-10, 2018.

[8] A. M. Taveira-DaSilva, T. C. Markello, D. E. Kleiner et al., "Expanding the phenotype of COPA syndrome: a kindred with typical and atypical features," Journal of Medical Genetics, vol. 56, pp. 778-782, 2018.

[9] F. Davatchi, C. Chams-Davatchi, H. Shams et al., "Behcet's disease: epidemiology, clinical manifestations, and diagnosis," Expert Review of Clinical Immunology, vol. 13, no. 1, pp. 57-65, 2017.

[10] E. Alpsoy, "Behçet's disease: a comprehensive review with a focus on epidemiology, etiology and clinical features, and management of mucocutaneous lesions," The Journal of Dermatology, vol. 43, no. 6, pp. 620-632, 2016.

[11] M. de Menthon, M. P. LaValley, C. Maldini, L. Guillevin, and A. Mahr, "HLA-B51/B5and the risk of Behçet's disease: a systematic review and meta-analysis of case-control genetic association studies," Arthritis \& Rheumatism, vol. 61, no. 10, pp. 1287-1296, 2009.
[12] Q. Zhou, H. Wang, D. M. Schwartz et al., "Loss-of-function mutations in TNFAIP3 leading to A20 haploinsufficiency cause an early-onset autoinflammatory disease," Nature Genetics, vol. 48, no. 1, pp. 67-73, 2016.

[13] R. Noorelahi, G. Perez, and H. J. Otero, "Imaging findings of Copa syndrome in a 12-year-old boy," Pediatric Radiology, vol. 48, no. 2, pp. 279-282, 2018.

[14] S. Volpi, J. Tsui, M. Mariani et al., "Type I interferon pathway activation in COPA syndrome," Clinical Immunology, vol. 187, pp. 33-36, 2018.

[15] J. Gálvez, "Role of Th17 cells in the pathogenesis of human IBD," ISRN Inflammation, vol. 2014, pp. 1-14, 2014.

[16] N. T. Sprenkle, S. G. Sims, C. L. Sánchez, and G. P. Meares, "Endoplasmic reticulum stress and inflammation in the central nervous system," Molecular Neurodegeneration, vol. 12, no. 1, pp. 42-59, 2017.

[17] B. O. Jensson, S. Hansdottir, G. A. Arnadottir et al., "COPA syndrome in an Icelandic family caused by a recurrent missense mutation in COPA," BMC Medical Genetics, vol. 18, no. 1, pp. 129-134, 2017.

[18] C. Xu and J. Min, "Structure and function of WD40 domain proteins," Protein \& Cell, vol. 2, no. 3, pp. 202-214, 2011. 




The Scientific World Journal
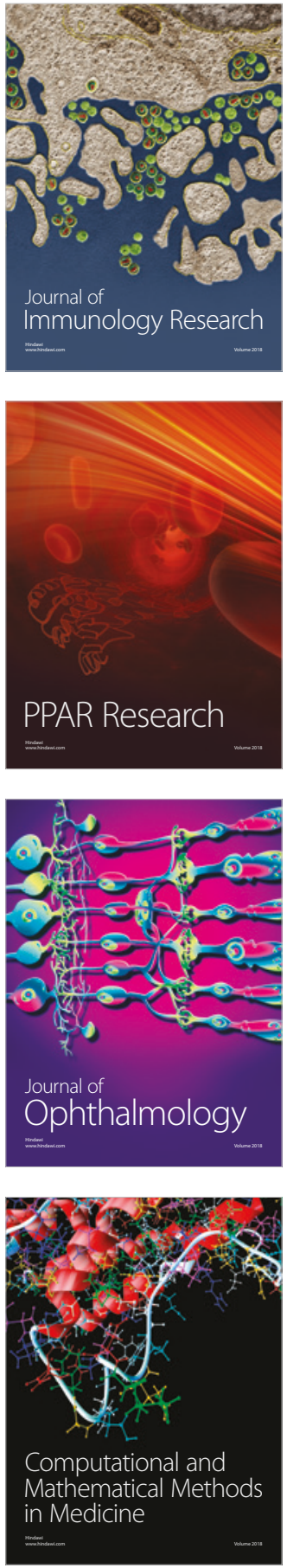

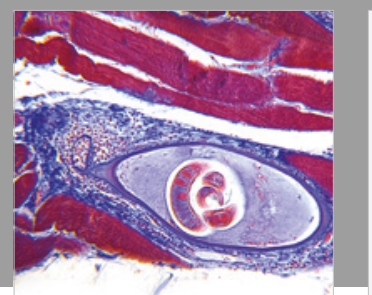

Gastroenterology Research and Practice

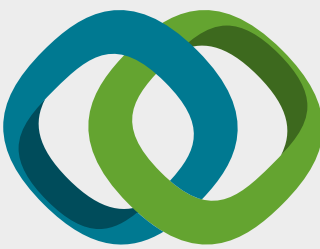

\section{Hindawi}

Submit your manuscripts at

www.hindawi.com
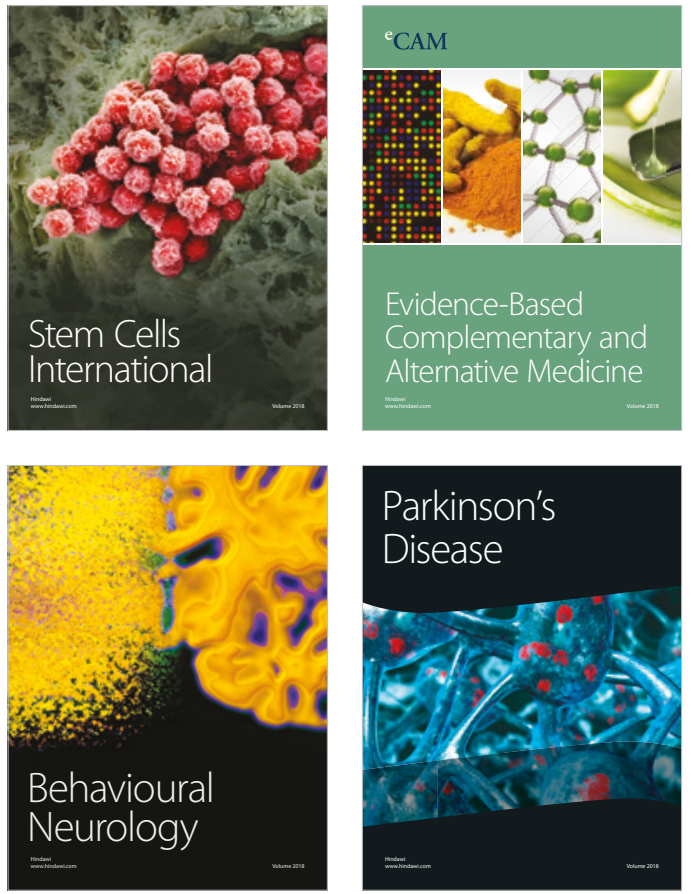

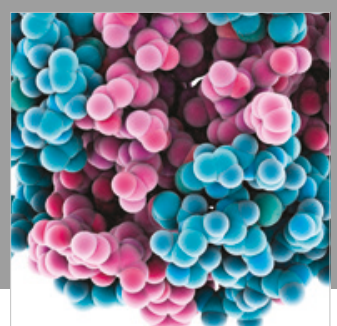

ournal of

Diabetes Research

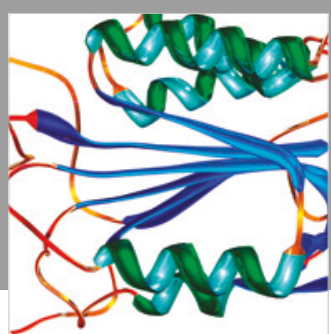

Disease Markers
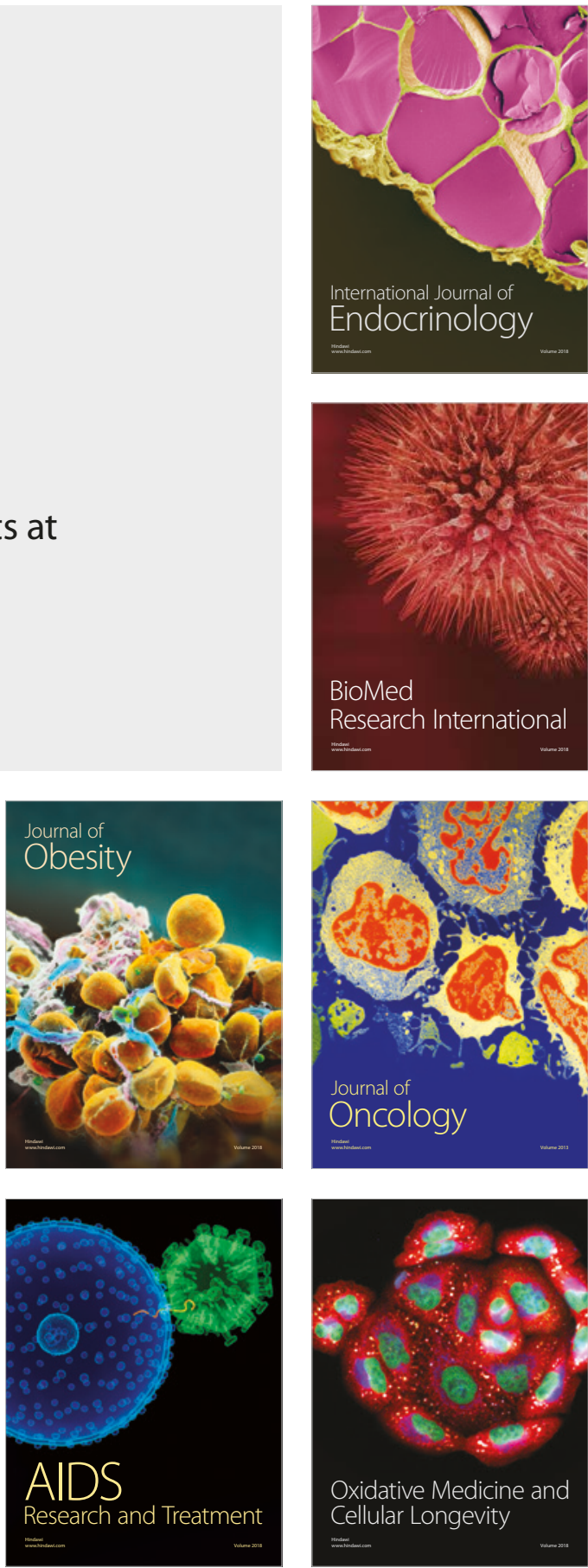